\title{
Isolation and structure determination of nematicidal iridoid sweroside from Alstonia scholaris
}

\author{
Nighat Sultana $^{1 \star}$, Musarrat Akhter ${ }^{2}$, Zafar Saeed Saify ${ }^{3}$, Zakia Khatoon², Mahmood-Ul-Hasan \\ Muhammed Saleem Qazi ${ }^{4}$ and Yousaf $\mathrm{Ali}^{5}$ \\ ${ }^{1}$ Pharmaceutical Research Center, PCSIR Laboratories Complex, Karachi-75280, Pakistan. \\ ${ }^{2}$ Food and Marine Resources Research Centre, PCSIR Laboratories Complex, Karachi-75280, Pakistan. \\ ${ }^{3}$ International Center for Chemical Sciences, H.E.J. Research Institute of Chemistry, University of Karachi, Karachi \\ 75270, Pakistan. \\ ${ }^{4}$ Departments of Biotechnology, University of Karachi, Karachi, Pakistan. \\ ${ }^{5}$ Medicinal Botanic Centre, PCSIR Laboratories Complex, Jamrud Road, Peshawar, Pakistan.
}

Accepted 10 May, 2013

\begin{abstract}
The methanol extract of aerial parts of Alstonia scholaris (sapthaparna) was found to possess good nematicidal activity against the plant parasitic nematode, Meloidogyne incognita. The active nematicidal compound was isolated from the methanol extract by column chromatographic techniques and purified by TLC. Chemical structure was determined by chemical and spectroscopic methods to be that of a sweroside. This is the first report of its isolation from A. scholaris. Among other pure compounds: 4, 6 and 7 , it showed maximum mortality of 71,89 and $91 \%$, respectively, after $24 \mathrm{~h}$, while after $48 \mathrm{~h}$, compounds 4,6 and 7 showed 88,74 and $76 \%$ mortality, respectively. The plant is of economic importance having nematicidal value. These results showed that the compounds isolated from $A$. scholaris have potent nematicidal activity and may be responsible for the antinematicidal activity of whole plant.
\end{abstract}

Key words: Meloidogyne incognita, Alstonia scholaris, iridoid, Apocynaceae, triterpenoids, nematicide.

\section{INTRODUCTION}

The context of our previous communication on phytochemical studies of the ethanolic extract of flowers of Alstonia scholaris of Pakistan origin, have resulted in the isolation of six triterpenoids, one of the oleanane type, alstoprenyol and four of the ursane type, alstoprenylene, $\alpha$-amyrin, $\beta$-amyrin and $3 \beta$-hydroxy-24-nor-urs-4,12,28triene triterpene. Now we reported the isolation of sweroside (1), $\alpha$-amyrin acetate (2) (Mahato and Sen, 1997), $\beta$-sitosterol (3), ursolic acid (4) (Brieskorn and Hofmann, 1962), $\beta$-sitosterol-3-O- $\beta-D$ glucopyranoside (5), lupeol (6), lupeol acetate (7), 3 $\beta$-acetate-24-nor-urs4,12-diene ester triterpene (8), stigma sterol (9) and 20 (30)-ursa-ene-3-ol (10) Figure 1 (Block et al., 1998) from the aerial parts of this plant. This study discusses and evolves methods for obtaining the plant extracts/pure compounds and its usages in order to act as a nematicidal agent. A bioassay guided isolation of the extract, fractions and pure compounds were subjected to nematicidal activity at different concentrations in comparison with Azadirachta indica. The crude alcoholic extract of aerial parts showed $95 \%$ and methanol fraction showed $80 \%$ mortality rate after $48 \mathrm{~h}$ at $1.0 \%$ concentration against Meloidogyne incognita.

Plant-parasitic nematodes constitute one of the most important pest groups of the economic crops, especially in the developed and developing countries of the world. 
The use of plants and plant products is one of the promising methods for nematode control. They are cheap, easy to apply, produce no pollution hazards and have the capacity to structurally and nutritionally improve the soil health. In view of these facts, investigations have been undertaken by various groups of scientists (Gommers, 1981; Qamar et al., 1995; Nogueira et al., 1996) which showed an effective control of root-knot nematodes. In the present article, studies on the nematicidal activity of the alcoholic, methanolic, chloroform, ethyl acetate, pet. ether extract, fractions and pure compounds isolated from the air-dried aerial parts of $A$. scholaris are described.

The genus Alstonia comprises about twelve species, seven of them are listed in Bentham's Flora of Australia. A. scholaris Linn. $\mathrm{R}$. Br. belongs to the family Apocynaceae (Kirtikar and Basu, 1980), grows throughout India, in deciduous and evergreen forests, and also in plains (Nadkarni, 1976). It is also widely distributed in the Asia-Pacific region from India, Sri Lanka through mainland South-East Asia and Southern China, throughout Malaysia to Northern Australia and Solomon Islands. The timber is a non-durable hardwood, suitable for light indoor construction purposes, pulp and paper production. The wood has been used for school blackboards, hence the name 'scholaris'. They are milk bearing shrubs or trees, with large, entire, generally whorled leaves, and terminal cymes of white flowers.

The plant $A$. scholaris has been used in different systems of traditional medication for the treatment of human diseases and ailments. It is reported to contain various alkaloids, flavonoids and phenolic acids. The bark contains alkaloids including ditaine, echitenine, echitamine (ditamine) and echitamidine together with triterpenes $\beta$ amyrin and lupeol. It has been reported as antimicrobial, antiamoebic, antidiarrhoeal, antiplasmodial, hepatoprotective, immunomodulatory, anti-cancer, antiasthmatic, free radical scavenging, antioxidant, analgesic, anti-inflammatory, anti-ulcer, anti-fertility, anaemia, chronic diarrhea, dysentery, menstrual disorders, malarial fever, colic and acute arthritis and wound healing activities (Dhar et al., 1977; Patil et al., 1999; Fell, 1954; Gandhi and Vinayak, 1990; Keawpradub et al., 1999). There are also reports available on the traditional use of this plant for its cardiotonic, anti-diabetic and anti-arthritic properties. The bark yields a tonic and antiseptic medicine. A con-centrated decoction of the trunk bark is used as a wash in furunculosis and impetigo, and as a gargle in dental caries. The bark, leaves and milky exudates of $A$. scholaris are used in India (Kirtikar and Basu, 1980; Nadkarni, 1976; The Wealth of India, Raw Materials, 2004; Pawan et al., 2011; Abhijit, 2011). Many isolated constituents from $A$. scholaris lack information on pharmacological activities (Patil et al., 1999; Fell, 1954; Gandhi and Vinayak, 1990; Keawpradub et al., 1999; Khan et al., 2003; Atta-urRahman et al., 2002).

Keeping in view the pharmacological significance of the plant, phytochemical studies were undertaken on the constituents of the aerial parts of the plant in this laboratory two years earlier, which resulted in the isolation and characterization of various pentacyclic triterpenoids (Sultana and Muhammed, 2010; Sultana et al., 2012). In the present study, a bio-activity directed isolation of the ethanolic extract showing nematicidal activity was undertaken which resulted in the isolation of an active iridoid and triterpenoid compounds. These compounds were identified as sweroside (1) and $\alpha$-amyrine acetate (2) (1), $\beta$-sitosterol (3), ursolic acid (4) (2), $\beta$-sitosterol-3-O- $\beta-D$ glucopyranoside (5), lupeol (6), lupeol acetate (7) through spectral studies (Sultana and Muhammed, 2010). This is the first report on the nematicidal activity (Sultana et al., $2010 \mathrm{a}, \mathrm{b})$ of sweroside and any part of $A$. scholaris.

\section{METHODS AND MATERIALS}

\section{General experimental procedures}

The mass spectra were recorded on a Jeol HX-110 instrument. The ${ }^{1} \mathrm{H}$ and ${ }^{13} \mathrm{C}-\mathrm{NMR}$ spectra were recorded in $\mathrm{CDCl}_{3}$ at $500 / 400$ and $125 / 75 \mathrm{MHz}$, respectively, on a Bruker AM-500, 400 NMR spectrometer. The UV and IR spectra were recorded on Shimadzu UV-240 and JASCO A-320 spectrophotometers, respectively. Optical rotations were measured on a polatronic $D$ Polarimeter. The purity of the compounds was checked on TLC (Si-gel, Merck $\mathrm{PF}_{254}, 0.25 \mathrm{~mm}$ thickness). Melting points were determined in glass capillary tubes using a Buchi 535 and a Gallenkamp 30/MF-370 melting point apparatus.

\section{Plant material}

The aerial parts of $A$. scholaris ( $5 \mathrm{~kg}$ ) were collected from the university campus, Kashmir, Pakistan, in October 2006. A voucher specimen (AKUH \# 58106) was deposited in the Herbarium of Department of Botany, University of Azad Kashmir, Pakistan.

\section{Extraction and isolation}

The aerial parts of $A$. scholaris ( $5 \mathrm{~kg}$ dry weight) were extracted with $\mathrm{EtOH}(50 \mathrm{~L})$. The EtOH extract was concentrated to a gum $(822 \mathrm{~g})$, dissolved in distilled water and extracted thoroughly with petrol ether $(25 \mathrm{~L})$. The petrol ether-soluble portion was evaporated under reduced pressure to yield a gum $(66.92 \mathrm{~g})$ which was chromategraphed on a silica gel column (Merck, 70-230 mesh, $2025.01 \mathrm{~g}$ ). The elution of the column was initiated with petrol ether. The combined column sub-fractions $1-8(5.91 \mathrm{~g})$ obtained by elution with 5:95 ethyl acetate-petrol ether, which showed similar TLC behavior upon spraying with ceric sulfate reagent, were combined and again subjected to CC using silica gel (type 60, 70-230 mesh, 200.10 g), and the column was eluted with petrol ether-ethyl acetate (99:1). The subfractions 6-30 (1.86 g), which showed similar TLC behavior were combined and further purified on preparative TLC plates using a solvent system of petrol ether-ethyl acetate (98:2) to afford pure compound $7(19.5 \mathrm{mg})$. The fractions obtained on elution of the column with $n$-hexane-ethyl acetate (10: 90$)$ were checked by TLC. Fractions 7-18 showing similar behavior on TLC were combined and further purified by preparative TLC (Merck PF254, $0.2 \mathrm{~mm}$ ) using 

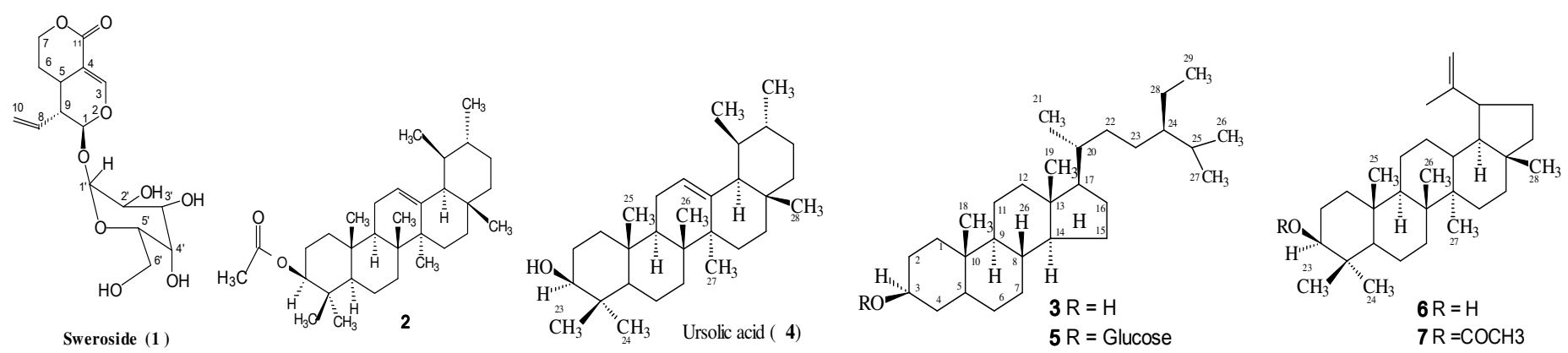

Figure 1. Triterpenes from Alstonia scholaris

$\mathrm{CHCl}_{3}$ as eluent to afford pure compound $2(28 \mathrm{mg})$. Elution of the major column which was loaded with $66.92 \mathrm{~g}$ of petrol ether-soluble material was eluted with $30 \%$ ethyl acetate-petrol ether to yield an impure mixture $(7.83 \mathrm{~g})$. This mixture was again subjected to CC (silica gel, 70-230 mesh, 60.20 g). The sub-fractions 6-30 (1.86 g), which showed similar TLC behavior, were combined and further purified on preparative TLC plates using a solvent system of petrol ether-ethyl acetate (90:10) to afford pure compound 3 (19.5 mg). The fractions obtained with 30:70 ethyl acetate-petrol ether yielded an impure compound 4, which was further purified by preparative TLC using a solvent system of petrol ether-ethyl acetate $(70: 30)$ to obtain pure $4(20 \mathrm{mg})$. Fractions $99-145(1.91 \mathrm{~g})$ obtained by elution with petrol ether-ethyl acetate $(35: 65,500 \mathrm{~mL}$ each) were collected and again subjected to CC (70-230 mesh, $60.20 \mathrm{gm})$. The sub-fractions 7-18 (0.92 g, $500 \mathrm{~mL}$ each) obtained with 80:20 petrol ether-ethyl acetate showed similar TLC behavior (ceric sulfateactive) and were combined and further purified on preparative TLC (Merck PF254, $0.2 \mathrm{~mm}$ ) using petrol ether-ethyl acetate 70:30 as eluent to obtain pure $5(28 \mathrm{mg}, R f=0.1)$. The remaining aqueous layer was extracted with methanol. The methanol soluble portion was dried as a crude mixture which was chromatographed on a Sigel column (Merck, 70-230 mesh, $30.28 \mathrm{~g}$ ). Elution of this column with $95 \% \mathrm{CHCl}_{3}: \mathrm{MeOH}(5 \mathrm{~L})$ yielded an impure mixture $(1 \mathrm{~g}, \mathrm{Fr} 5$ 15) $500 \mathrm{ml}$ each containing compound 1 , this mixture was chromatographed on $\mathrm{SiO}_{2}$ gel column $(2 \times 70 \mathrm{~cm}$, Merck. 70-230 mesh, $322 \mathrm{~g})$ and eluted with $\mathrm{CHCl}_{3}(100 \%)$, followed by $2: 8 \mathrm{MeOH}$ : $\mathrm{CHCl}_{3}$ to afford 30 fractions (5-10) afford 1.

\section{Nematicidal Activity}

Experiments were performed under laboratory conditions at $28 \pm$ $2^{\circ} \mathrm{C}$. Fresh egg masses collected from stock culture maintained on tomato root tissues were kept in water for egg hatching. The larvae emerged after $48 \mathrm{~h}$ from the egg masses incubated at $30^{\circ} \mathrm{C}$ and were used as test species for larval mortality studies (Nighat et al., 2011). The movements of the nematodes were checked by touching them with the needle. Stock solutions $(30 \mathrm{mg} / \mathrm{ml})$ of the fractions and pure compounds were prepared. To determine the nematicidal effect of the various fractions and the pure compounds, 100 freshly hatched second-stage juveniles were taken in $5 \mathrm{ml}$ of tap water. Freshly hatched second stage juveniles were used, while distilled water with nematode larvae was taken as control.

A measured amount of stock solution was added to make dilutions of $0.5,0.25,0.125$ and $0.05 \%$. Standard nematicide $A$. indica was taken for comparison and tap water was taken as control. After $48 \mathrm{~h}$ of exposure with Buddleja crispa fractions and pure compounds, the larvae were counted for mortality and nonmortality under stereoscopic microscope. The death of the nematodes was confirmed by keeping them in tap water for $24 \mathrm{~h}$. The percent mortality was worked out from an average of three replicates.

\section{RESULTS AND DISCUSSION}

Hepatoprotective compound sweroside (1) was isolated as a yellowish gummy substance from the methanol extract of aerial parts of $A$. scholaris by column and thinlayer chromatography. Compound $1\left(\mathrm{C}_{16} \mathrm{H}_{22} \mathrm{O}_{9}\right)$ was identified by comparison of its data with those reported earlier, which was originally isolated as a major constituent from Centaurium spicatum and from Swertia mileensis (He and Nie, 1980) and this is the first report of its isolation from this plant. The spectral data of compounds 2-7 also compared well with reported compounds, (+)- previously isolated from plants (Mahato and Sen, 1997; Brieskorn and Hofmann, 1962; Block et al., 1998).

A bio-assay guided isolation of the alcoholic extract of the air-dried aerial parts of $A$. scholaris yielded seven nematicidal compounds (1-7) showing nematicidal activity at $0.5,0.25,0.125$ and $0.05 \%$, respectively. The structures of these constituents were earlier reported (Mahato and Sen, 1997; Brieskorn and Hofmann, 1962; Block et al., 1998; Sultana, 2011) through chemical and spectroscopic methods including one-dimensional $\left({ }^{1} \mathrm{H}-\mathrm{NMR},{ }^{13} \mathrm{C}\right.$ NMR, broad band and DEPT) and two-dimensional (COSY-45, NOESY, J-resolved, hetero COSY) NMR techniques. The nematicidal activity of the crude alcoholic extract (AS-AS), its fractions (AS-MS, AS-CS and AS-PS) as well as pure compounds (1-7) were tested against a root-knot nematode $(M$. incognita). The direct antinemic action shown by $A S$ and its fractions in the in vitro investigation against second-stage juveniles of $M$. incognita is presented in Tables 1 to 2 . The crude alcoholic extract (AS) showed $80 \%$ mortality at $1.0 \%$ concentration after $24 \mathrm{~h}$, and $95 \%$ mortality at $1.0 \%$ concentration after $48 \mathrm{~h}$, whereas the methanol soluble fraction (AS-MS) showed $80 \%$ mortality, and the hexane soluble fraction (AS-PS) showed $40 \%$ mortality at the same concentration after 48 h. Conventional nematicide $A$. Indica showed $90 \%$ mortality. The alcoholic soluble (AS), methanol soluble (AS MS), and pet.ether soluble (AS-PS) fractions showed 80, 75 
Table 1. Nematicidal activity of different fractions isolated from $A$. scholaris on the larval mortality of $M$. incognita (root-knot nematode).

\begin{tabular}{lccccc}
\hline \multirow{2}{*}{ Fraction } & \multicolumn{5}{c}{ Percent mortality/concentration after $\mathbf{2 4} \mathbf{~ h}$ (\%) } \\
\cline { 2 - 6 } & $\mathbf{1 . 0}$ & $\mathbf{0 . 5}$ & $\mathbf{0 . 2 5}$ & $\mathbf{0 . 1 2 5}$ & $\mathbf{0 . 0 0}$ (control) \\
\hline AS-AS & 80 & 72 & 70 & 42 & 02.00 \\
AS-MS & 75 & 65 & 60 & 55 & 00.00 \\
AS-PS & 32 & 30 & 25 & 20 & 03.00 \\
Azadirachta indica & 88 & 85 & 73 & 58 & 00.00 \\
\hline
\end{tabular}

Values represent the mean of 3 experiments. AS-AS (alcohol soluble), AS-MS (methanol soluble), AS-PS (pet.ether soluble).

Table 2. Nematicidal activity of different fractions isolated from $A$. scholaris on the larval mortality of $M$. incognita (root-knot nematode).

\begin{tabular}{lccccc}
\hline \multirow{2}{*}{ Fractions } & \multicolumn{5}{c}{ Percent mortality/concentration after $\mathbf{4 8} \mathbf{~} \mathbf{( \% )}$} \\
\cline { 2 - 6 } & $\mathbf{1 . 0}$ & $\mathbf{0 . 5}$ & $\mathbf{0 . 2 5}$ & $\mathbf{0 . 1 2 5}$ & $\mathbf{0 . 0 0}$ (control) \\
\hline AS-AS & 95 & 83 & 60 & 55 & 3.00 \\
AS-MS & 80 & 78 & 72 & 65 & 2.00 \\
AS-PS & 40 & 35 & 28 & 22 & 4.00 \\
Azadirachta indica & 90 & 87 & 80 & 60 & 2.00 \\
\hline
\end{tabular}

Values represent the mean of 3 experiments.

Table 3. Nematicidal activity of compounds (1-7) on M. incognita larvae after $24 \mathrm{~h}$.

\begin{tabular}{lccccc}
\hline \multirow{2}{*}{ Compound } & \multicolumn{5}{c}{ Percent mortality/concentration after $\mathbf{2 4} \mathbf{h}$ (\%) } \\
\cline { 2 - 6 } & $\mathbf{1 . 0}$ & $\mathbf{0 . 5}$ & $\mathbf{0 . 2 5}$ & $\mathbf{0 . 1 2 5}$ & $\mathbf{0 . 0 0}$ (control) \\
\hline Sweroside (1) & 80 & 68 & 40 & 20 & 0.0 \\
a-Amyrin acetate (2) & 36 & 31 & 22 & 21 & 2 \\
$\beta$-sitosterol (3) & 57 & 44 & 42 & 22 & 2 \\
Ursolic acid (4) & 71 & 64 & 50 & 30 & 4 \\
$\beta$-sitosterol-3-O-, $\beta$-D glucopyranoside (5) & 72 & 55 & 47 & 35 & 4 \\
Lupeol (6) & 89 & 41 & 36 & 36 & 2 \\
Lupeol acetate (7) & 91 & 61 & 55 & 55 & 4 \\
Azadirachta indica & 88 & 85 & 73 & 58 & 0.0 \\
\hline
\end{tabular}

Values represent the mean of 3 experiments.

and $32 \%$ mortality, respectively, after $24 \mathrm{~h}$, of $M$. incognita larvae. Seven pure compounds (1-7) were isolated from the methanol and hexane fractions and their nematicidal activity tested on $M$. incognita larvae. The results of the in vitro valuation are shown in Tables 3 to 4 .

Compound 1 showed highest mortality (92\%) at $1.0 \%$ concentration, while 4 and 5 showed 88 and $80 \%$ mortality, respectively at the same concentration after $48 \mathrm{~h}$. Conventional nematicide $A$. indica showed $90 \%$ mortality at the concentrations used in the present studies. The pure compounds 2, 3, 6 and 7 showed $36,57,89,91 \%$ mortality, respectively, after $24 \mathrm{~h}$, while after $48 \mathrm{~h}$, compounds showed $40,69,74,76 \%$ mortality, respectively for $1.0 \%$ concentration. Nematicidal activity on 1 , $0.5,0.25$ and $0.125 \%$ concentration and control is given in Tables 3 to 4.
It was noted that at all the concentrations, all the tested fractions and pure compounds exhibited significant larval mortality against the test nematode but the activity decreases with a decrease in concentration in all the cases (Tables 1 to 4).

\section{Conclusion}

The plant is of economic importance and has nematicidal value. Phytochemicals are used in many medicines, insecticides, pesticides, especially for plant diseases. Those plants which have these proportions can be used in the manufacture of nematicide (Javed et al., 2006). It is evident from the above discussion that there is a great likelihood of use of biocontrol agents for disease control by nematodes (Javed, et al., 2007; Jiskani et al., 2005). 
Table 4. Nematicidal activity of compounds (1 -7) on $M$. incognita larvae after $48 \mathrm{~h}$.

\begin{tabular}{lccccc}
\hline \multirow{2}{*}{ Compound } & \multicolumn{5}{c}{ Percent mortality/concentration after $\mathbf{4 8} \mathbf{~} \mathbf{( \% )}$} \\
\cline { 2 - 6 } & $\mathbf{1 . 0}$ & $\mathbf{0 . 5}$ & $\mathbf{0 . 2 5}$ & $\mathbf{0 . 1 2 5}$ & $\mathbf{0 . 0 0}$ (control) \\
\hline Sweroside (1) & 92 & 85 & 78 & 71 & 3 \\
$\square$-Amyrine acetate (2) & 40 & 34 & 25 & 22 & 2 \\
$\beta$-Sitosterol (3) & 69 & 64 & 45 & 40 & 3 \\
Ursolic acid (4) & 88 & 70 & 68 & 55 & 5 \\
$\beta$-sitosterol'3-O-, $\beta$-D glucopyranoside (5) & 80 & 73 & 50 & 30 & 5 \\
Lupeol (6) & 74 & 70 & 57 & 45 & 3 \\
Lupeol acetate (7) & 76 & 71 & 53 & 40 & 2 \\
Azadirachta indica & 90 & 87 & 80 & 60 & 2 \\
\hline
\end{tabular}

Values represent the mean of 3 experiments.

Although, several potential bio-control agents have been isolated and tested for their efficacy against soil born root pathogens, there is need to discover new potential antagonists or improve strains of already isolated antagonists for better crop production (Jiskani et al., 2005). Development of a sample, cheap and effective method for mass production of bio-control agents is a pre-requisite for the replacement of chemical fungicides by a biocontrol agent which also needs investigation.

\section{REFERENCES}

Abhijit Dey (2011). Alstonia scholaris R.Br. (Apocynacease): Phytochemistry and pharmacology: A consie review. J. Appl. Pharm. Sci. 01 (06): 51-57.

Atta-ur-Rahman, Sultana N, Choudhary MI (2002). Triterpene and Coumarins from Skimmia laureola. Nat. Prod. Lett. 16:305 - 313.

Block LC, Scheidt C, Quintão NL, Santos AR, Cechinel-Filho V (1998), Phytochemical and pharmacological analysis of different parts of Wedelia paludosa DC. (Compositae). Pharmazie 53:716-718.

Brieskorn $\mathrm{CH}$, Hofmann $\mathrm{H}$ (1962). On the quantitative determination of ursolic acid and oleanolic acid by means of the Liebermann-Burchard reaction, Arch. Pharm. 295/67, 505 - 509.

Dhar DN, Suri SC, Dwivedi $P(1977)$. Chemical examination of the flowers of Alstonia scholaris, Planta Medica 31:33-4.

Fell C, Johnson JF, Seegers WH(1954). Effects of Seitz filtration on plasma trace proteins concerned with blood coagulation; a quantitative study. 24(2):153-60.

Gandhi M, Vinayak VK (1990). Preliminary evaluation of extracts of Alstonia scholaris bark for in vivo antimalarial activity in mice. J. Ethnopharmacol. 29:51-7.

Gommers FJ (1981). Biochemical inter-actions between nematodes and plants and their relevance to control. Helmin-thol. Abstr. 50B, 9-24.

He RY, Nie RL(1980). Studies on bitter principles from Swertia moleensis, Acta Botan. Yunnan. 2:480-482.

Javed N, Anwar SA, Inam ul Haq M, Ahmad R, Khan HU (2006). Effect of neem formulations applied as soil drenching on invasion and development of root-knot nematode, Meloidogyne javanica. In: Proceeding of International Symposium on Sustainable Crop Improvement and Integrated Management. University of Agriculture, Faisalabad, Pakistan on September 14-16. pp. 244-247.

Javed N, Gowen SR, Inam ul Haq M, Sarwar SA (2007), Protective and curative effect of neem (Azadirachta indica) formulations on the development of rootknot nematode, Meloidogyne javanica in roots of tomato plants. Crop Prot. 26:530-534.

Jiskani MM, Nizamani SM, Wagan KH, Mugheri AN, Memon JA, Soomro SH (2005). Efficacy of some biocontrol agents, alongwith mustard cake and furadan on growth and multiplication of
Meloidogyne incognita infecting tomato plants, Pak. J. Nematol. 23: 81-86.

Keawpradub N, Kirby GC, Steele JC, Houghton PJ, Keawpradub N, Kirby GC, Steele JCP, Houghton PJ (1999). Antiplasmodial activity of extracts and alkaloids of three Alstonia species from Thailand, Planta Medica 65:690-4.

Khan MR, Omoloso AD, Kihara M (2003). Antibacterial activity of Alstonia scholaris and Leea tetramera. Fitoterapia 74 (7-8), 736-40.

Kirtikar KR, Basu BD (1980). Indian Medicinal Plants, Bhushen Singh and Mahendra Pal Singh, Dehradun, Vol. II, 111

Mahato SB, Sen S (1997). Advances in triterpenoid research, 19901994. Phytochemistry 44:1185-1236.

Nadkarni AK (1976). Nadkarni, KM. Nadkarni's Indian Materia Medica, Popular Prakashan, Bombay, Vol. I, 80

Nighat S, Musarrat A, Muhammad S, Yousaf A (2011). Nematicidal effect of Acacia nilotica and Gymnema sylvestris against second stage juveniles of Meloidogyne incognita. J. Entamol. Nematol. 3(2): 25-29.

Nogueira MA, de Oliveira JS, Ferraz S, (1996). Nematicidal hydrocarbons from Mucuna aterrima, Nematicidal hydrocarbons from Mucuna aterrima. Phytochemistry 42 (4), 997-998.

Patil RS, Juvekar AR, Joglekar SN, Shamkuwar PB, Nimbkar SR(1999). Study of antidiarrhoeal activity of Alstonia scholaris bark. Indian Drugs 36: 463-465

Pawan K, Dhirender K, Neha S, Rana AC (2011). Alstonia scholaris: It's Phytochemistry and pharmacology, Chronics of young scientists 2(2): $71-78$

Qamar F, Kapadia Z, Khan SA, Badar Y (1995). Datura metel L. a plant with nematicidal potential. Pak. J. Sci. Ind. Res. 38(8):319-321.

Sultana N, Muhammed S (2010). Phytochemical studies on Alstonia scholaris, Z. Naturforsch 65b:203-210.

Sultana N (2011). Clinically useful anticancer, antitumour and anti wrinkle agent, ursolic acid and related derivatives as medicinally important natural product. J. Enzyme Inhib. Med. Chem. 26 (5):616642.

Sultana N, Akhter M, Khatoon Z (2010a). Nematicidal natural products from Rubus niveus. Nat. Prod. Res. 24:407-415.

Sultana N, Akhter M, Afza N, Rashid AK, Malik A (2010b). Nematicidal natural products from Buddleja crispa. Nat. Prod. Res. 24: 783-788.

Sultana N, Zafar Saeed Saify, Muhammad S, Mustafa K (2012). Two new triterpenes from Alstonia scholaris flowers, Natural Product Research, Formerly Natural Product Letters, 1-10, iFirst (online published).

The Wealth of India, Raw Materials (2004). Vol. I,CSIR, New Delhi. pp. 50 